\title{
Evaluation of explanation of the BASNEF model on smoking waterpipe among the students one of the medical universities located in the south of Iran
}

\begin{abstract}
Background and Objective: The current evidences have indicated that the prevalence of smoking cigarette and waterpipe has an ascending trend among the university students since their first year of study. The present study aimed to evaluation of explanation of the BASNEF model on smoking waterpipe among the university students.

Materials and Methods: This cross-sectional study was conducted on 462 students selected by proportional stratified random sampling. The study data were collected using demographic questionnaire and researcher-made questionnaire based on the "BASNEF" model. The collected data were then entered into the SPSS statistical software (v. 19) and analyzed using descriptive statistics, Pearsons correlation coefficient and Regression analysis.

Results: The prevalence rates of smoking cigarette and waterpipe were $11.7 \%$ and $16.6 \%$, respectively. The results showed no significant difference in using cigarette or waterpipe by gender $(p<0.01)$. The participants' mean scores of attitudes, subjective norms, and enabling factors were $72.96 \pm 14.95,21.51 \pm 5.31$, and $19.1 \pm 4.04$, respectively, regarding behavioral intent, $35.28 \%$ of consumers said they would never stop smoking waterpipe, and only $4.32 \%$ said they were more likely to quit smoking waterpipe within the next month.

Conclusion: Considering the prevalence of smoking waterpipe and cigarette among the students and the relatively inappropriate attitudes, subjective norms, and enabling factors to quit smoking, educational interventions based on interpersonal models to prevent or quit high-risk behaviors are suggested.

Keywords: Water pipe, Cigarette, University students, BASNEF Model

Paper Type: Research Article.
\end{abstract}

Citation (Vancouver): Kaveh MH, Jafari A, Keshavarzi S, Momenabadi V, Taheri M, Dehbozorgi F, Motazedian T. Evaluation of explanation of the BASNEF model on smoking waterpipe among the students one of the medical universities located in the south of Iran. Iran J Health Educ Health Promot. Winter 2020;7(4): 312-322. [Persian]

> Citation (APA): Kaveh MH., Jafari A., Keshavarzi S., Momenabadi V., Taheri M. Dehbozorgi F., Motazedian T. (Winter 2020). Evaluation of explanation of the BASNEF model on smoking waterpipe among the students one of the medical universities located in the south of Iran. Iranian Journal of Health Education \& Health Promotion., 7(4)312-322. [Persian]
Mohammad Hossein Kaveh

* Associate Professor, Research Center for Health Sciences, Institute of Health, Department of Health Education and Promotion, Shiraz University of Medica Sciences, Shiraz, Iran (Corresponding author).Email: kaveh@sums.ac.ir

Alireza Jafari

MSC graduate, Department of Health Education and Promotion, School of Health, Shiraz University of Medical Sciences,Shiraz, Iran

Sareh Keshavarzi

Assistant Professor, Department of Epidemiology, School of Health, Shiraz University of Medical Sciences, Shiraz, Iran.

Victoria Momenabadi

$\mathrm{PhD}$ in Health Education and Promotion, Department of Public Health, Schoo of Health, Bam University of Medical Sciences, Bam, Iran.

Mostafa Taheri

MSC graduate, Department of Health Education and Promotion, School of Health, Shiraz University of Medical Sciences, Shiraz, Iran.

Farzaneh Dehbozorgi

MSC graduate, Department of Health Education and Promotion, School of Health, Shiraz University of Medical Sciences, Shiraz, Iran.

Tal-at Motazedian

MSC graduate, Department of Health Education and Promotion, School of Health, Shiraz University of Medical Sciences, Shiraz, Iran.

Received: 14 October 2018 Accepted: 27 December 2019

DOI: 10.29252/ijhehp.7.4.312 


\section{ارزيابى تبيين كنندَى مدل بزنف بر ميزان مصرف قليان در دانشجويان يكى از دانشعاههاى علوم يزشكى جنوب ايران}

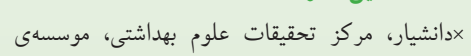

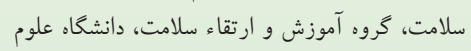

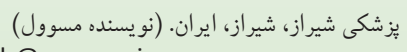
kaveh@sums.ac.ir.

عليرضا جعفرى كارشناس ارشد آموزش بهداشت و ارتقاء سلامت، گروه

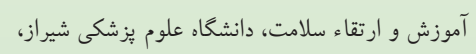
شيراز، يران.

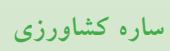

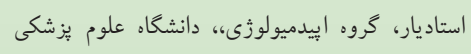

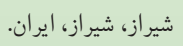

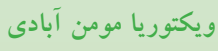

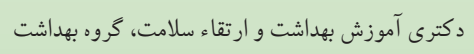
عمومى، دانشكاه علوم يزشكى بم، بم، ايران. مصطفى طاهرى مارشى كارشناس ارشد آموزش بهداشت و ارتقاء سلامت، كروه

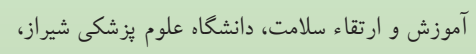

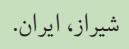

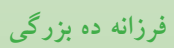
كارشناس ارشد آموزش بهداشت و ارتقاء سلامت، گروره

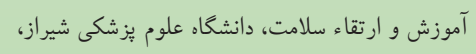
شيراز، ايران. - ان.

طلعت معتضديان كارشناس ارشد آموزش بهداشت و ارتقاء سلاء سلامت، كروه

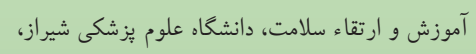
شيراز، ايران.

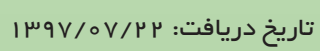

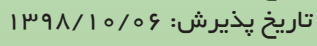

\section{0}

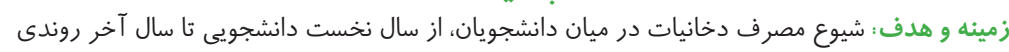

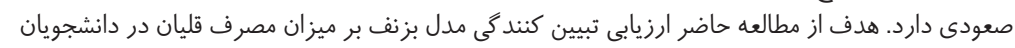
با استفاده از مدل مارد. هدف از مونف است.

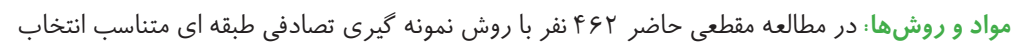

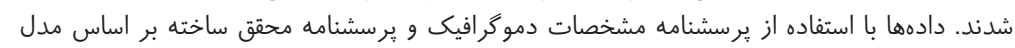

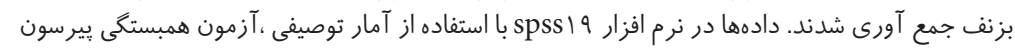

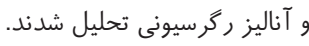

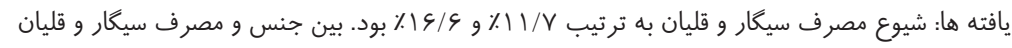

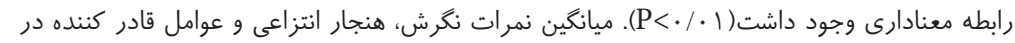

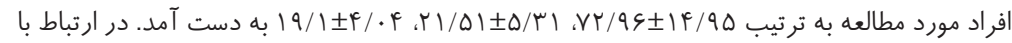

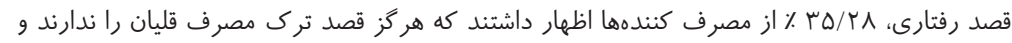

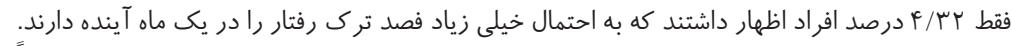

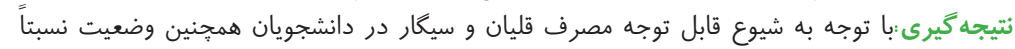

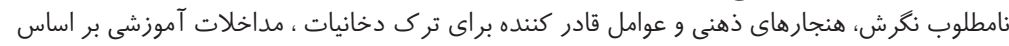

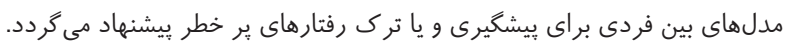

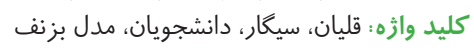

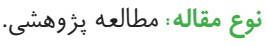

4 استناد (ونكوور): كاوه م، جعفرى ع، كشاورزى س، مومن آبادى و، طاهرى م، ده بزرگى في ف، معتضديان

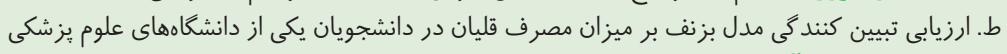

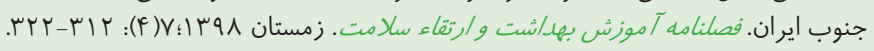

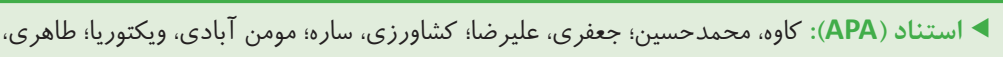

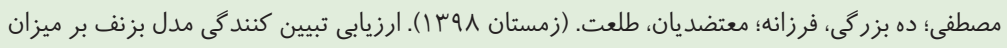

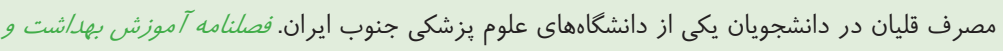


كزارش گرديد(9) در ايران، روند شيوع مصرف مواد دخانى در

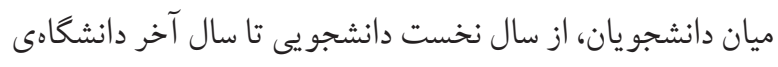
صعودى گز ارش شده است ( • (). در يكى از دانشخاههاى ايران نيز

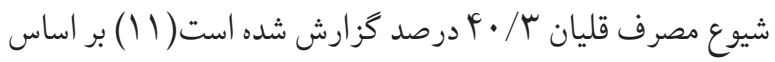

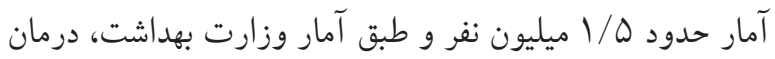

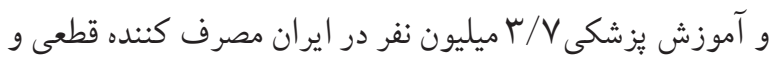

$$
\text { تفننى مو اد دخانى هستند( (I ). }
$$

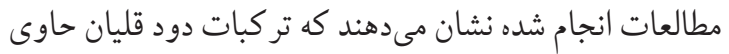
مقادير زيادى از مواد سرطان زا از قبيل هيدروكربنها و فلزات سنگئنين

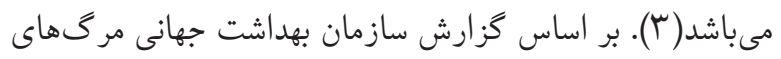

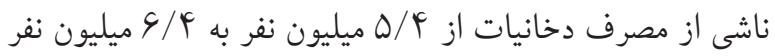

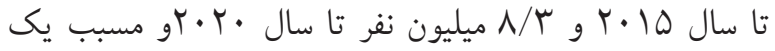

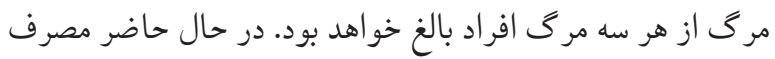
دخانيات جهارمين علت مرى در سراسر دنيا است( سار). عمده ترين بيمارىهاى مرتبط با مصرف دخانيات كه جزء علل عمده مرى

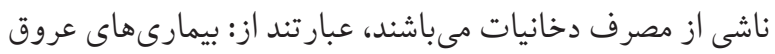
كرونر قلب، بيمارىهاى ريوى مثل برونشيت مزمن و آمفيزم، سرطانهاى ريه، لب، حنجره، مرى و يانكراس. همجٍنين استعمال

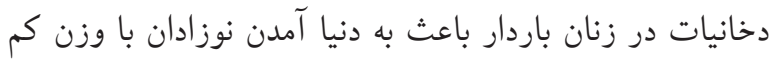

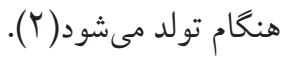

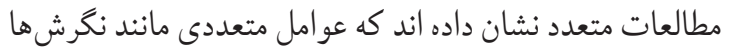
و باورهاى مختلف در مورد مضرات كمتر قليان نسبت به سيكار، ارزان بودن قليان، در دسترس بودن و طعمهاى مختلف و متنوع در شيوع مصرف قليان نقش دارند(I I ( ). با توجه به اينكه رفتار بر خطر مصرف قليان در بين دانشجويان

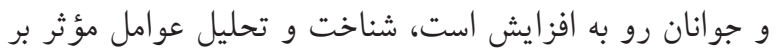

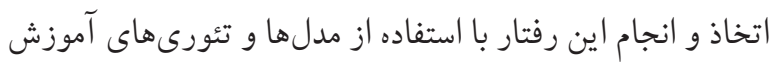

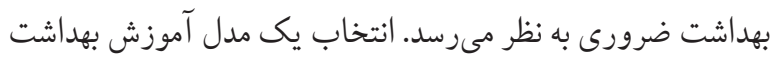

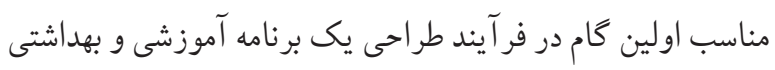

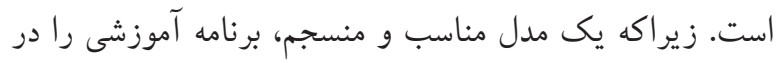
مسير صحيح آغاز و آن را در جهت حركت صحيح نكه مىدارد و
اعتياد براى هر جامعهى انسانى توام با خساراتى است كه جنبههاى اقتصادى، اجتماعى، فرهنكى، سياسى و انسانى رادر بر ميى گيرد.

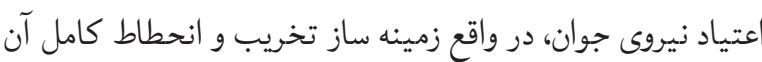

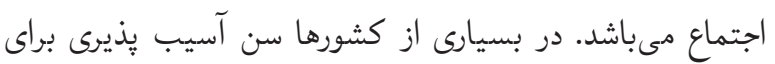

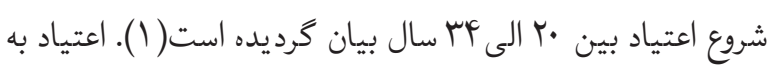

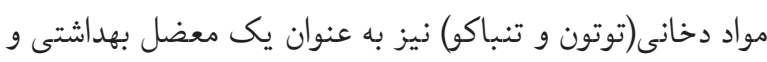
همه جانبهى بشر متمدن در دنيا مطرح مى باشد(Y).

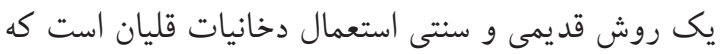

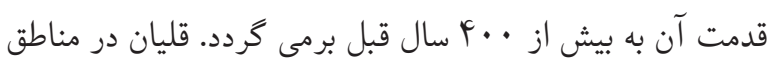

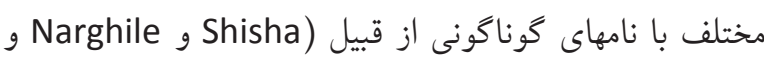

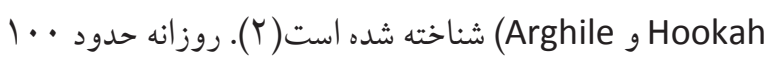
ميليون نفر در جهان قليان مصرف مى كنند. حتى در بعضى مناطق

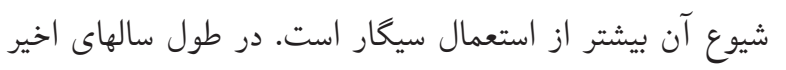

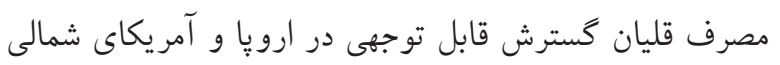

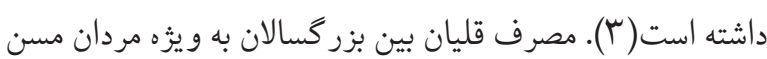
در جوامع آسيايى و آفريقايى خصوصا خاور ميانه و كشورهاى دئي

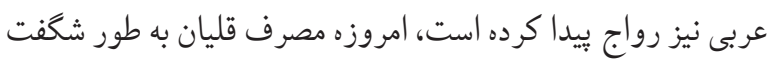

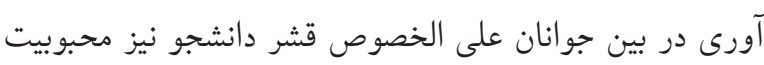

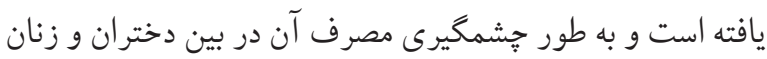

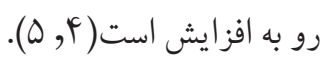

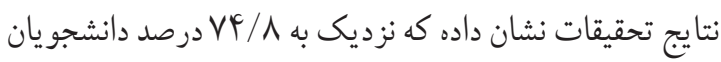

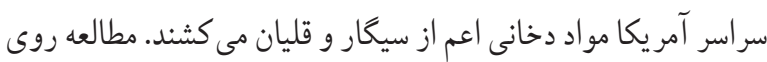
دانشجويان دو دانشگاه در آمر يكا نشان داد كه 19 1\% از دانشجويان

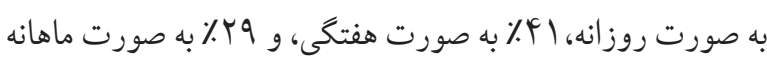

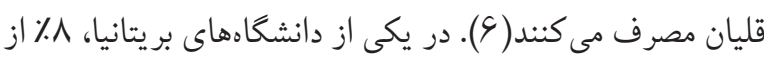
دانشجو يان به صورت منظم قليان مصرف مى كنند) (V). طبق نتايج مطالعات انجام شده مصرف قليان در بين دانشجويان

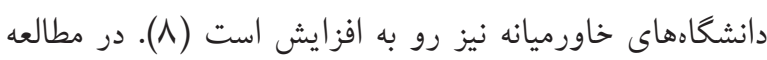

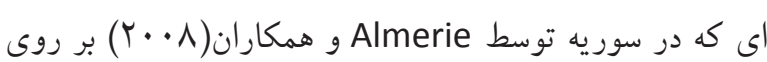

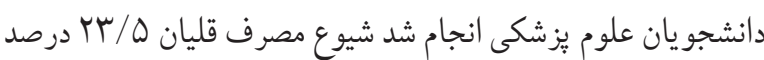


سيخارى و مهمتر ين باورهاى غلط رايج در خصوص استعمال سيكار:

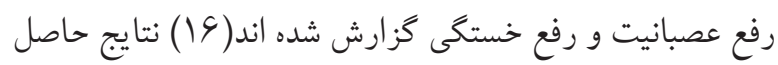

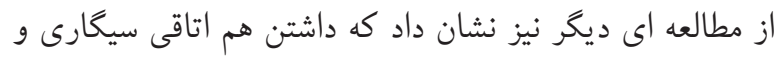

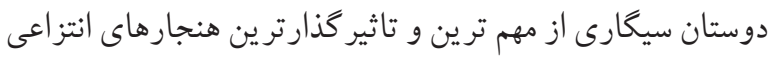
براى مصرف سيكار بودند. دسترسى آسان، سهولت مصرف و ارزان بودن قيمت سيخار نيز از مهم ترين عوامل قادر ساز تشخيص داده شدند. (IV) اما با توجه به شيوع بالاى مصرف قليان در بين جو عرانان

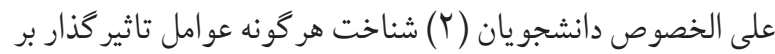

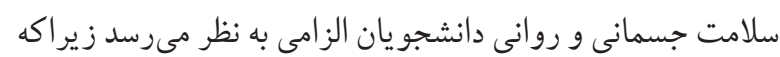

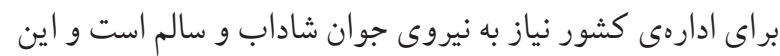
درحاليست كه سرمايههاى مادى و معنوى بسيارى نيز براى تعليم

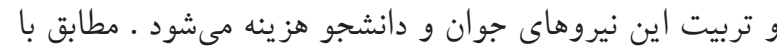
جستجوهاى انجام شده توسط محققين ثزوهش حاضر، در مطالعات

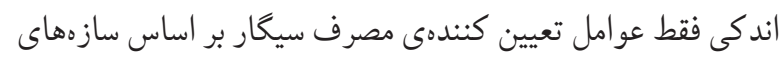

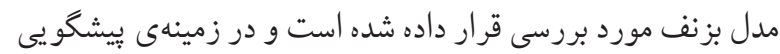

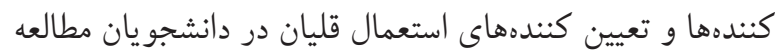
اى يافت نشد لذا ضرورت انجام مطالعهى حاضر احساس گرديد.

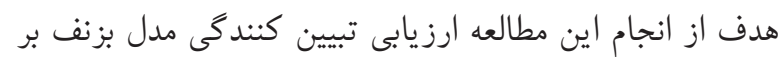

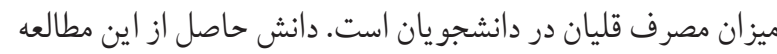

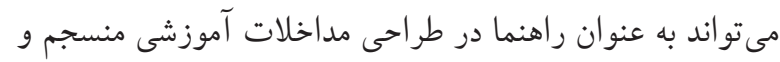

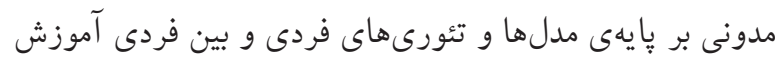
بهداشت و ارتقاء سلامت استفاده شود.

مو اد و روش ها يُّوهش حاضر يك مطالعهى مقطعى از نوع توصيفى مىباشد كه

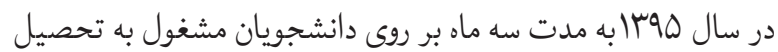
در دانشكدههاى تابعه ى(دانشكدهى بهداشت، تغذيه، برستارى و

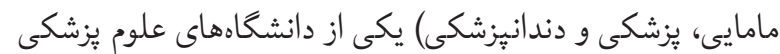
واقع در جنوب ايران(دانشكاه علوم يزشكى شيراز انجام شده است.

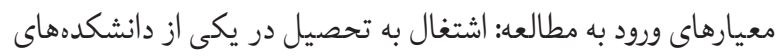

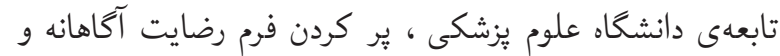

در كنار نيازهاى اساسى بهداشتى به عنوان يك يشتوانه، اثربخشى

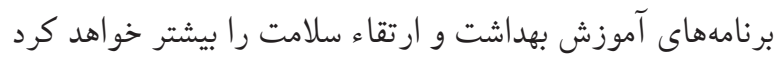
همجِنين به درك و تعيين عناصر اساسى براى تغيير رفتار در دراز

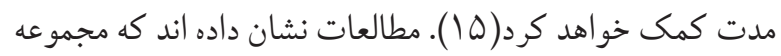

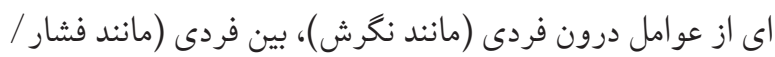
حمايت اجتماعى)، و محيطى (مانند فراهمى و دسترسى) در رفتار

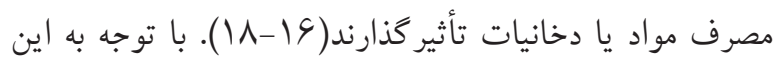

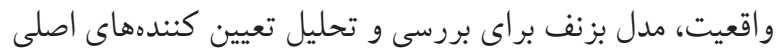

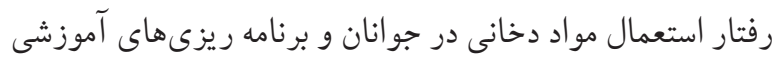
براى آنها مناسب تر به نظر مىرسد( 19 (1). مدل بزنف از مدلهاى رايج در مبحث تغيير رفتار و وييش بينى رفتار مىباشد. مدل بزنف از f سازه تشكيل شده است. اولين سازهى مدل مذكور نكرش است و اشاره به احساس كلى فرد، يعنى دوست

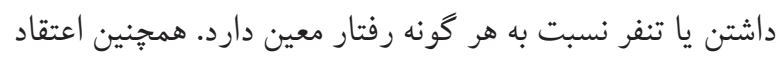
به نتايج رفتار و ارزيابى شخص از نتايج رفتار نيز نغرش فرد را شكل مى دهد. دومين سازه نرمهاى انتزاعى است و اشاره دارد به باور

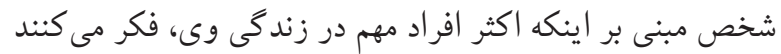

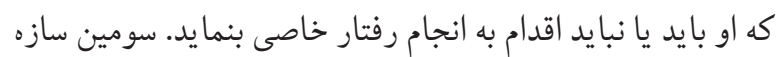

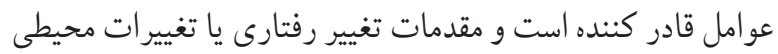
محسو ب شده كه اجازه تحقق يك انگيزش را مىدهد نظير: دستيابى به منابع، در دسترس بودن، قوانين، مقررات، مهارتها؛ اين عوامل روى قصد رفتارى فرد براى انجام رفتار تاثير گذار مىباشد. طبق اين مدل مهمتر ين تعيين كننده رفتار فرد، قصد رفتارى است زيرا

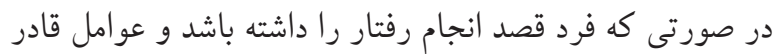
كننده هم مهيا باشند مى تواند منجر به انجام رفتار شوند. اين مدل تركيبى از مدل عمل منطقى و يُرسيد-يروسيد مىباشد( 19 - (Y).

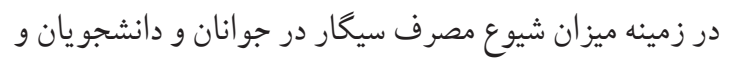

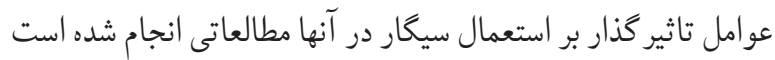
براى نمونه، در يزوهشى كه با استفاده از مدل بزنف در كرمانشاه

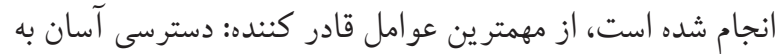
سيكار و ارزان بودن سيكار، بيشتر ين نرم انتزاعى: تأثير دوستان 
كنيد؟ ب - اخردر حال حاضر قليان مصرف ميكنيد تا جه حد

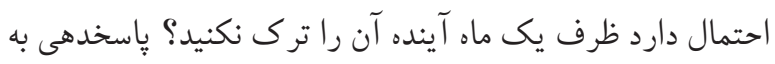
اين سؤالات در قالب مقياس ليكرت (خيلى زياد تا خيلى كم) با دارديا نمره دهى التا له بود. بخش نكرش شامل آT سؤال در قالب سو الات ليكرت (خيلى

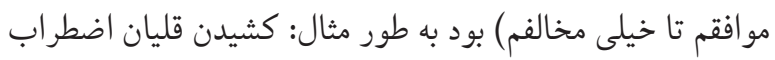

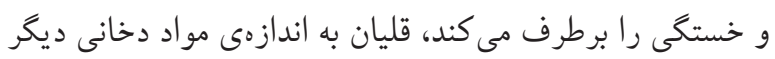
مثل سيكار اعتيادآور نيست. بخش هنجار انتزاعى شامل ه سوال در قالب سو الات ليكرت

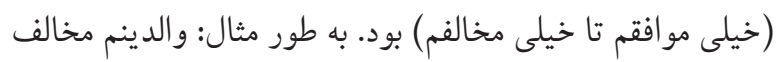
قليان كشيدن من هستند، ، دوستانم موافق قليان كشيدن من هستند.

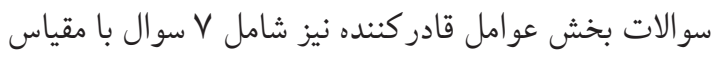

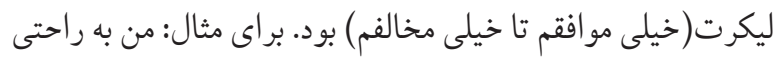

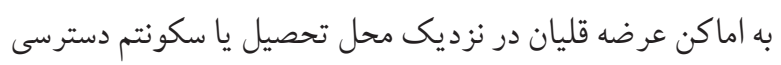

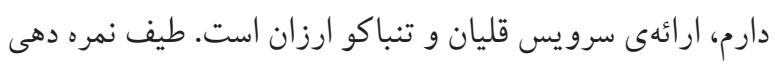
در سازههاى نكرش، هنجار انتزاعى، و عوامل قادر كننده به ترتيب

$$
\text { D • }
$$

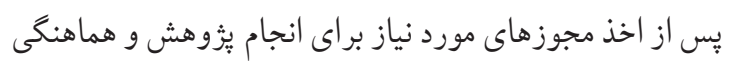

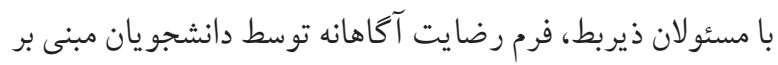
شر كت داوطلبانه در اين يُزوهش تكميل گرديد و به آنان اطمينان

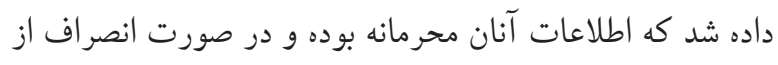
مطالعه هيج كونه ضرر و زيان مادى و معنوى متوجه آنها نخواهد بود همجنين برسشنامها بى نام و با ذكر كد جمع آورى شدند. .

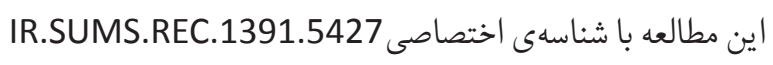

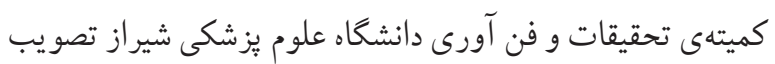
شده است

جهت تجزيه و تحليل دادهها از نرم افزار آمارى19 SPSS

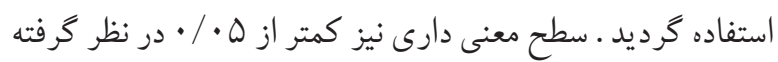

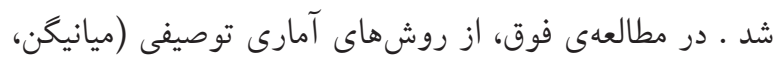

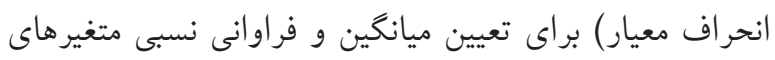

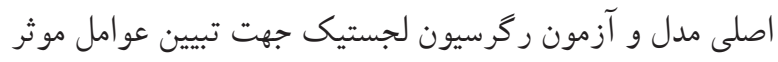

سابقهى كشيدن سيگار و يا قليان در سه ماه كذشته بود. معيار خروج از مطالعه: عدم رضايت براى شركت در يُوهش و تكميل نكردن صحيح و يا كامل يرسشنامه بود.

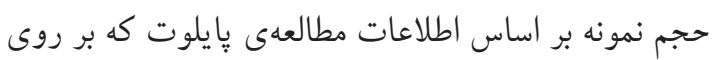
•م دانشجوى مشغول به تحصيل در دانشكدهاى دانشعاه علوم

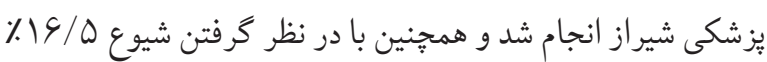

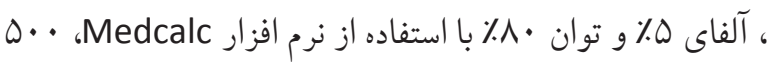
نفر تعيين گرديد.

در يُزوهش حاضر به دليل اينكه مى خواستيم از همهى دانشكدهها

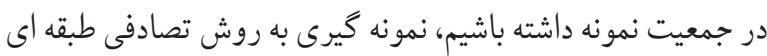
متناسب انجام شد.( هر يك از دانشكدههاى زير مجموعهى دانشكاه

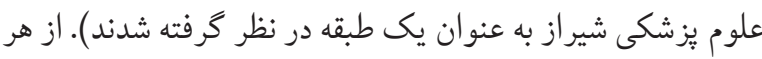
دانشكده نمونهها به روش تصادفى ساده انتخاب گرديد يدند.

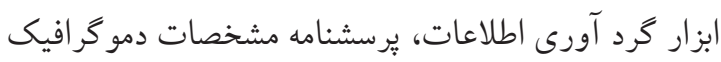

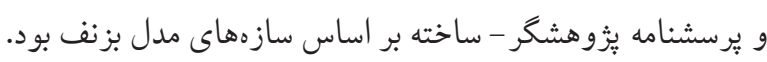

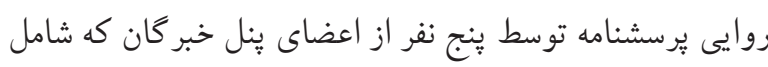

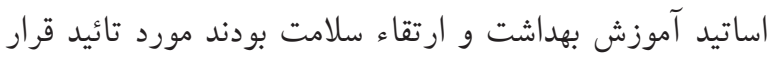

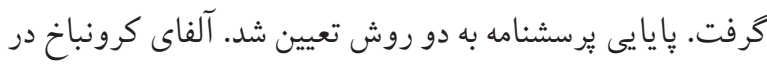
تك تك سازههاى مدل بدين صورت بدست آمد: سازه قصد رفتار

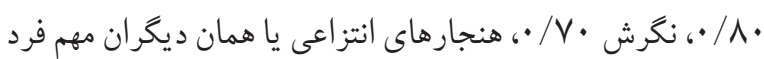

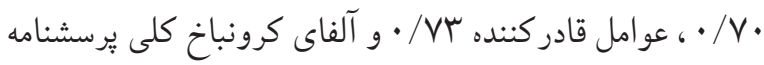

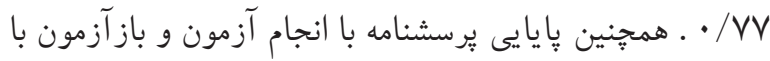

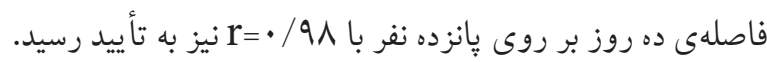

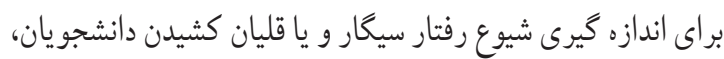
در مورد وضعيت فعلى مصرف سيكار و يا قليان كشيدن از آنها سوال يرسيده شد كه بايد با مقياس بلى و خير پِاسخ مى دادند. (نمونه سؤال:

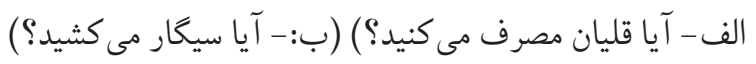

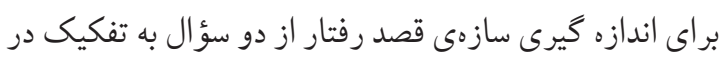
ارتباط با ترك مصرف قليان و يا احتمال ادامهى استعمال قليان

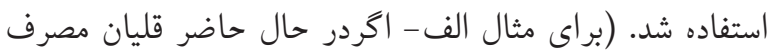

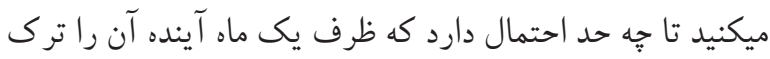


كسب شده در افراد مورد مطالعه F/ P / 19/I مىباشد. از بين

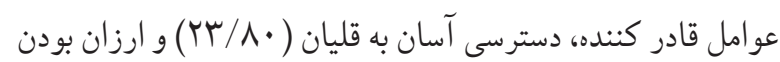

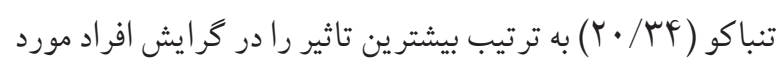
مطالعه به سمت استعمال قليان داشتند(جدول ()). جدول ا. توزيع فراوانى عوامل موثر بر رفتار قليان كشيدن بر اساس

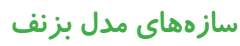

\begin{tabular}{|c|c|c|c|}
\hline 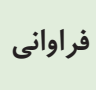 & 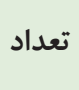 & فاكتورهاى موثر بر رفتار & سازههاى \\
\hline$r \Delta / \cdot c$ & ISr & دوستان & \multirow{5}{*}{ 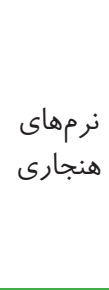 } \\
\hline$r \mu / \Lambda$. & 11. & والدين الد & \\
\hline$r \cdot / \Delta \varphi$ & 90 & شخصيتهاى هنرى و ورزشى & \\
\hline $\mid f / \cdot G$ & 90 & شخصيتهاى دانشگاهى & \\
\hline$s / 4 q$ & r. & همسرم & \\
\hline درصد & تعداد & فاكتورهاى موثر بر رفتار & سازمهاى \\
\hline$r \mu / \Lambda$. & 11. & دسترسى آسان & \multirow{7}{*}{ ق ادمر كننده } \\
\hline$r \cdot / \mu r$ & $9 f$ & 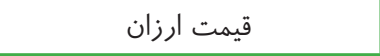 & \\
\hline $\mid \Delta / \Delta \lambda$ & Vr & نداشتن قبح اجتماعى در جامعه به كشيدن & \\
\hline$r / \varsigma V$ & IV & عدم ممنوعيت مصرف در خوابگاه & \\
\hline $19 / 94$ & $\checkmark V$ & طعمهاى متنوع تنباكو & \\
\hline $11 / r \Delta$ & $\Delta r$ & دورهمىهاى دوستانه & \\
\hline$\Lambda / 90$ & r. & بر كردن اوقات فراغت و بيكارى & \\
\hline درصد & تعداد & فاكتورهاى موثر بر رفتار & سازمهاى \\
\hline $01 / 9 F$ & rF. & موافق كشيدن قليان & \multirow{3}{*}{ 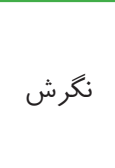 } \\
\hline $19 / 91$ & 94 & 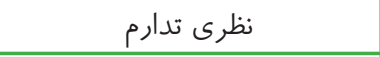 & \\
\hline rN/Ir & $1 \mu$. & مخالف كشيدن قليان & \\
\hline
\end{tabular}

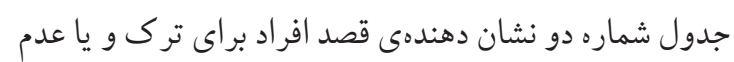

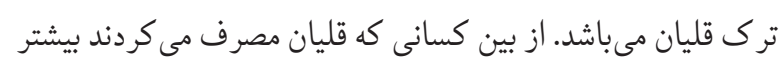

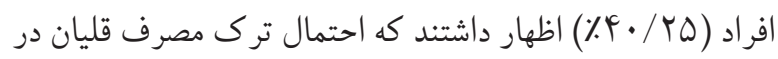

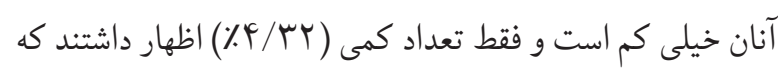
احتمال ترى مصرف قليان در يك ماه آينده در آنان خيلى زياد

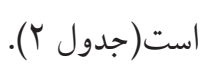

بر شيوع قليان استفاده كرديد.

يافته ها

در اين مطالعه از ..0 يرسشنامه اى كه بين دانشجويان توزيع شده

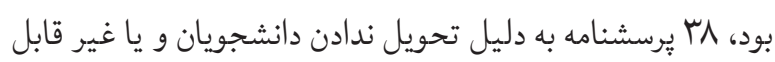

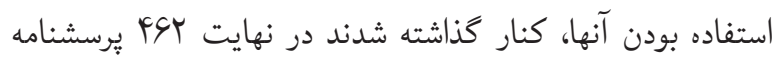

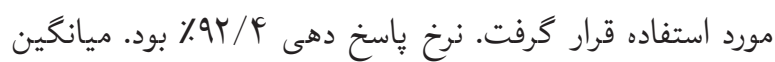

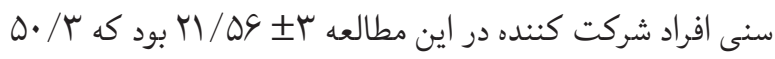

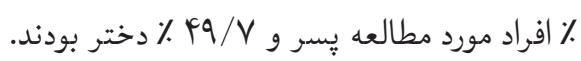

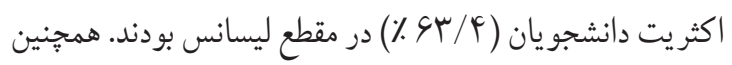

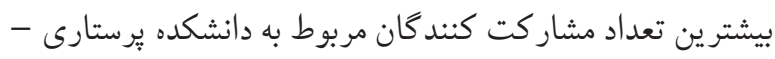

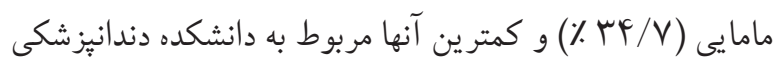

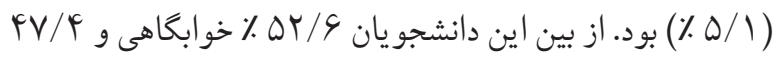

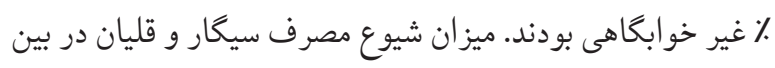

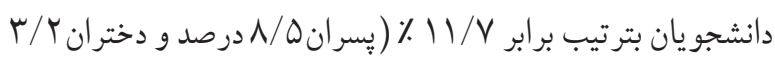

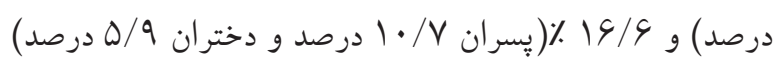

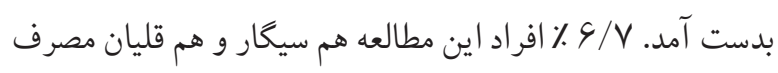
مى كردند. همانطور كه بيشتر بيان شد طيف نمرات قابل اكتساب دردر

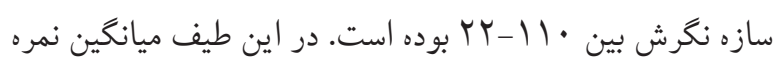

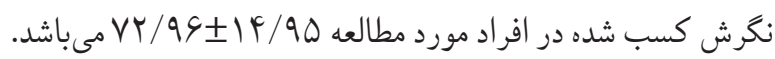

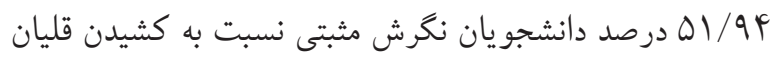

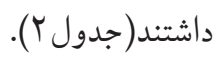

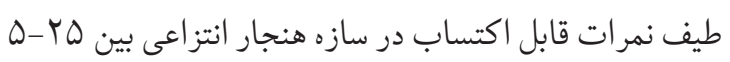
بوده است. در اين طيف ميانخين نمره هنجار انتزاعى كسب شده

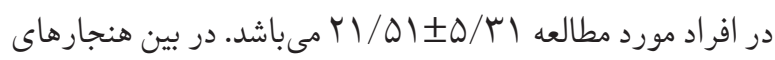

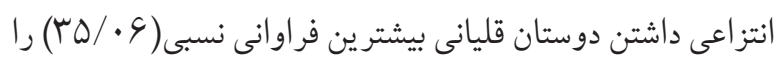
در بين عوامل موثر بر رفتار قليان كشيدن دانشجويان مورد مطالعه دئه داشت(جدول ا). طيف نمرات قابل اكتساب در سازه عوامل قادر كننده بين Dr بوده است. در اين طيف ميانكين نمره عوامل قادر كننده 
جدول r. مقايسه توزيع درصد(فراوانى نسبى) افراد مورد مطالعه بر حسب سطوح قصد رفتارى

\begin{tabular}{|c|c|c|c|c|c|c|c|}
\hline معنى دارى & هر گز & خيلى كم & كم & زياد & خيلى زياد & & \\
\hline \multirow[t]{2}{*}{$\mathrm{p}<\cdot / \cdots 1$ 米 } & س & 119 & $s q$ & rq & $r$. & تعداد & \multirow{2}{*}{ آينده در مصرف ترك مصرف قنيدان فعان در يك ملى قليان } \\
\hline & $r \Delta / r \Lambda$ & $F \cdot / r \Delta$ & $1 \pi / \wedge 0$ & $s / r V$ & $r / \mu r$ & فر اوانى & \\
\hline
\end{tabular}

* Significant at $\alpha=0 / 05$

مصرف افزايش بيدا مى كند (IV) ). لذا مطالعهى فوق به بررسى ميزان

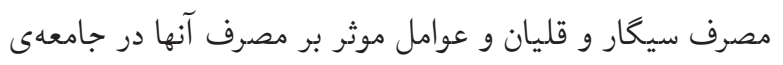
دانشجويى برداخته است.

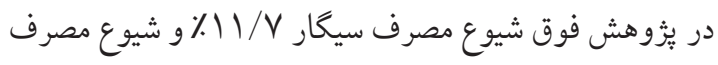

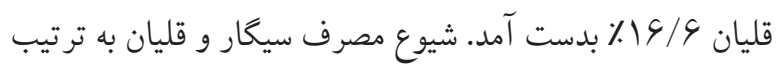

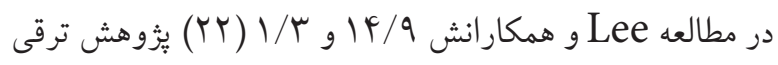

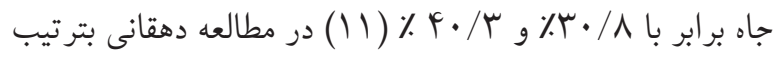

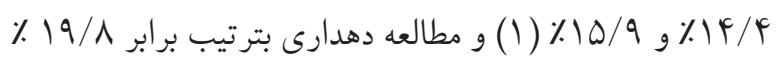

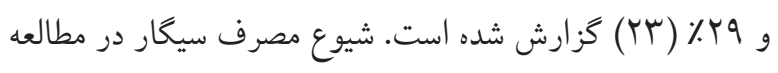

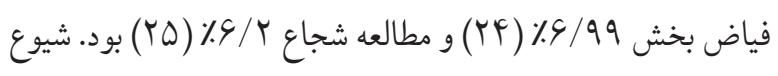

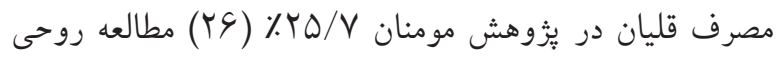

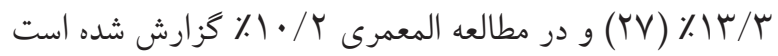

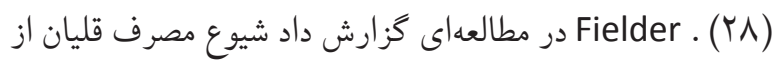

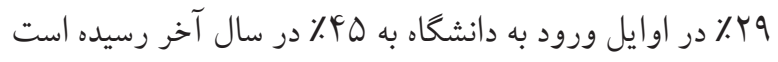

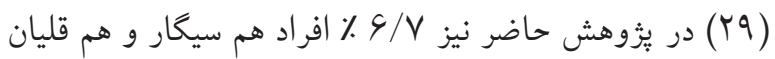

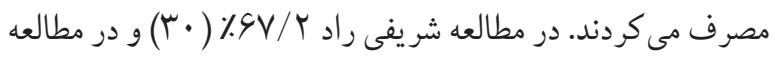

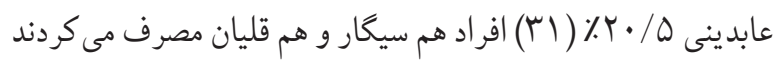

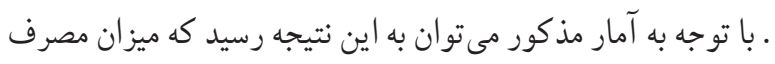

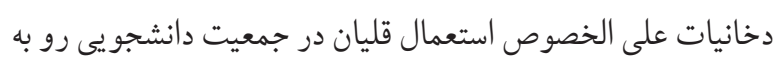
افزايش است كه اين نشان دهندهى بذيرش اجتماعى قليان و باور غلط

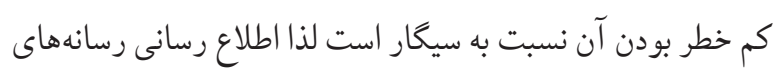

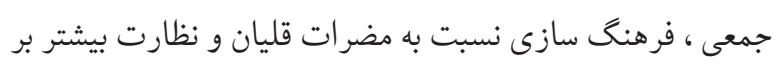

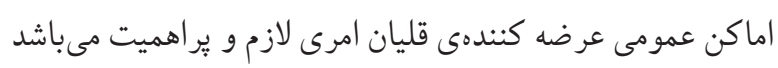

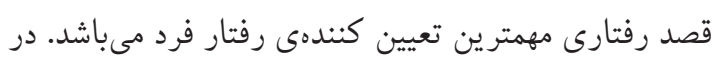

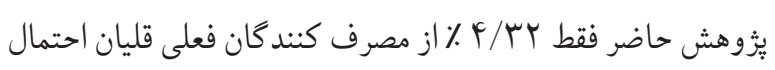

بر طبق نتايج تحليل ركرسيون لجستيك مهمتر ين عوامل بيش

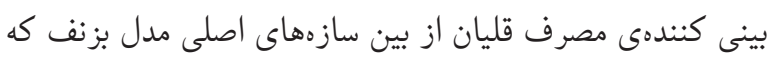
تاثير بر روى قصد رفتار (مهمتر ين تعيين كنندهى رفتار) ميكذارند،

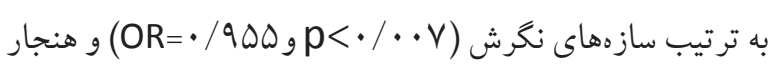

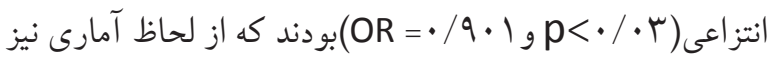

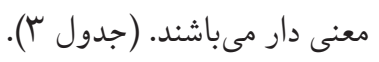
جدول س. شاخصهاى تحليل سازههاى وارد شده به معادله

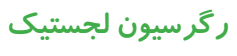

\begin{tabular}{|c|c|c|c|c|}
\hline سطح معنى & سطح اطمينان در & شانست & ضريب بتا & متغير \\
\hline 米. $/ \cdots V$ & $\begin{array}{c}-\cdot / 9 r \mu \\
. / 911\end{array}$ &.$/ 900$ & $-\cdot 1 \cdot 4 c$ & ن ن ن \\
\hline 米./.r & $\begin{array}{c}-\cdot / 1 \mathrm{r} . \\
\cdot / 99 .\end{array}$ & $\cdot / 9 \cdot 1$ & $-\cdot / 1 \cdot r$ & هنجارهاى ذهنى \\
\hline$\cdot|r \&|$ & $\begin{array}{c}-\cdot / \wedge \mu \varsigma \\
1 / \cdot \Delta\end{array}$ &.$/ 9 \mu \mathrm{V}$ & -.1 .90 & قادر كننده ها \\
\hline
\end{tabular}

* Significant at $\alpha=0 / 05$

* Stepwise method

$$
\text { بحث و نتيجه كيرى }
$$

استعمال دخانيات يكى از معظلات كنونى جوامع بيشرفته و در

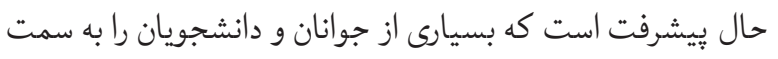

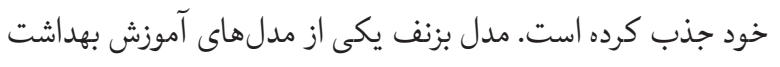
است كه به عوامل فردى و بين فردى تاثيرگذار بر انجام يا عدم

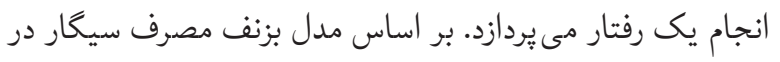

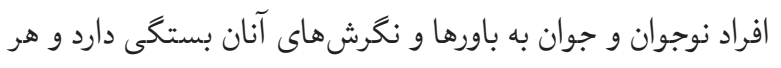

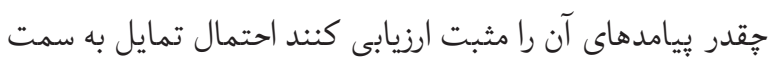


بيشتر از دختران بودهو از نظر آمارى هم معنادار بوده است (IV)

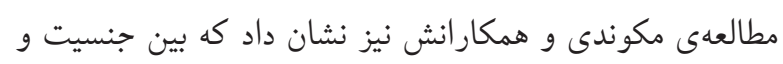

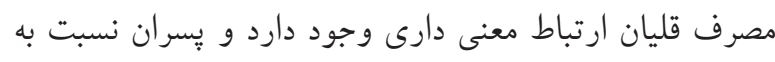

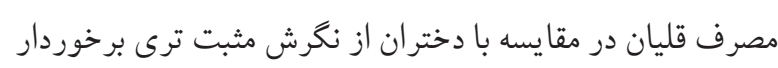

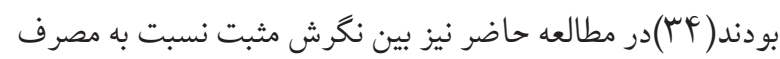

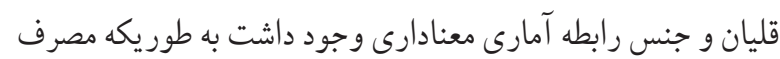

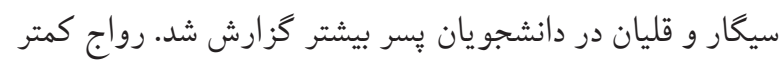
مصرف سيخار و قليان در بين دختران مىتواند به دو علت باشد دوند

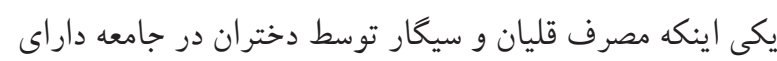

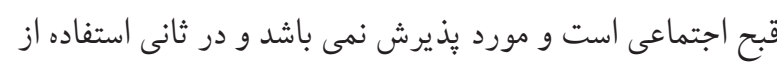

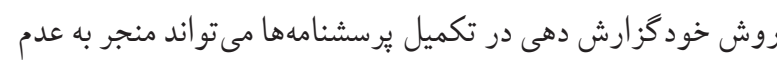

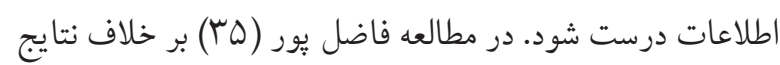

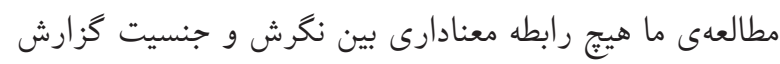

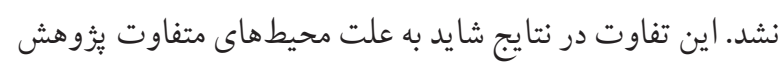
و يا تفاوت در ابزارهاى اندازه كيرى باشد.

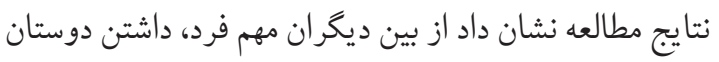

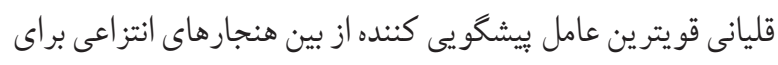

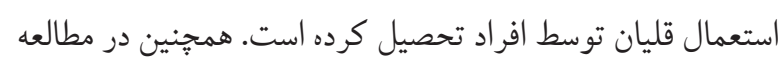
جر كزى داشتن هم اتاقى و دوستان سيخارى از مهمتر ين ديكران مهم

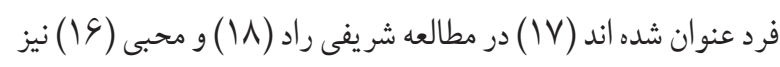

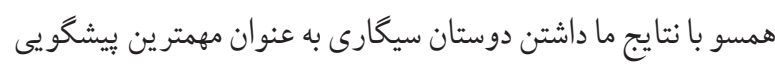

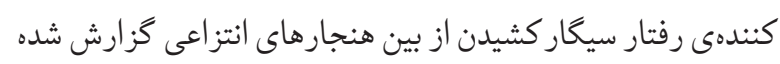

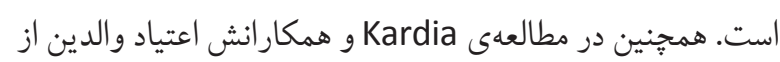

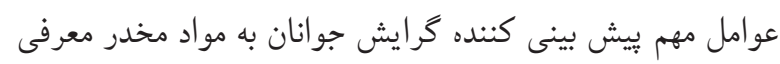

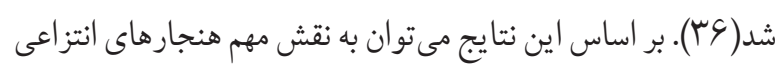

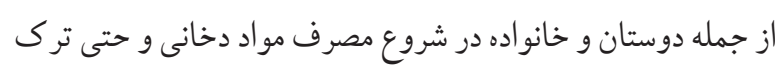

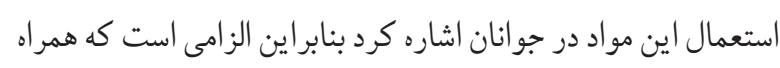
با بالا بردن سطح آكاهى فردى در مورد مضرات مواد دخانى، ديكران

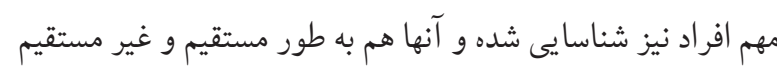

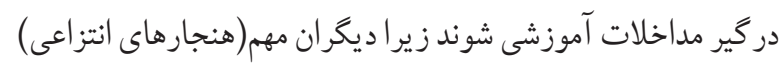

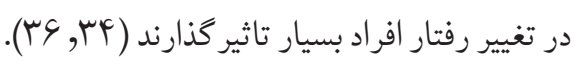

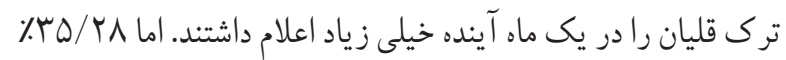
آنان عنوان كردند كه اصلا قصد ترك قليان را در يك ماه مآ آينده

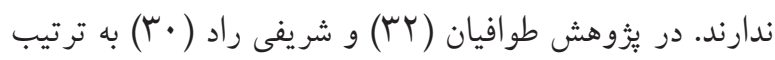

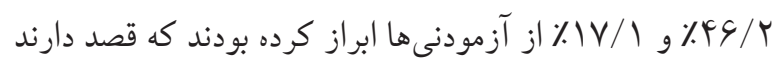

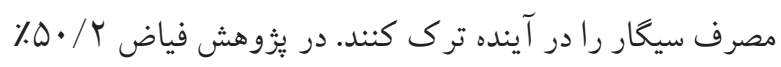

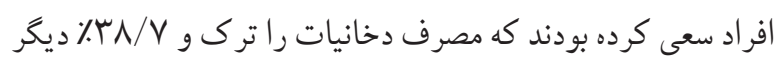

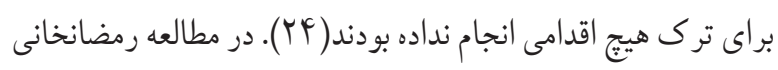
تقريبا از هر ه نفر مصرف كننده سيعار ا نفر براى ترك سيخار اقدام كرده بود(سץ). اين نتايج نشان مى دهد كه جهت ترك سيخار و قليان نيز تاسيس مكانهايى همانند كلينيكهاى ترى اعتياد همراه

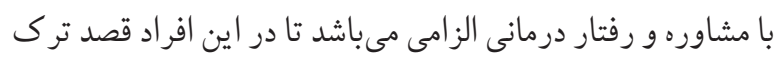

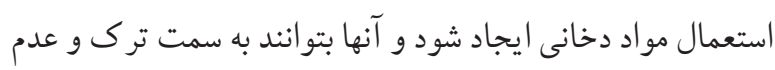

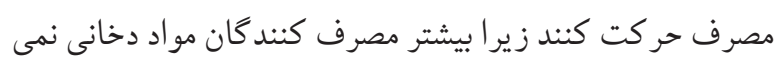
دانند براى ترك و مشاوره به جه مكانى بايد مراجعه كنند.

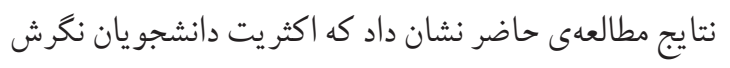
مثبتى نسبت به مصرف قليان داشتند و موافق كشيدن قليان بودند در مطالعهى ترقى جاه و همكارانش نيز همسو با نتايج ما دانشجويان

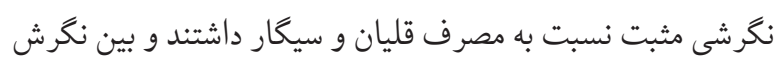
مثبت آنها و اعتيادشان به سيخار و قليان رابطهى معنى دارى وجود نيك داشت(1) (1) نتايج مطالعهى فياض بخش و همكار انش در دانشكاه تهران نيز نشان داد كه اكثريت دانشجويان نسبت به مصرف قليان نكرش مثبتى دارند و اين نكرش مثبت در پرنسران بيشتر از دختران

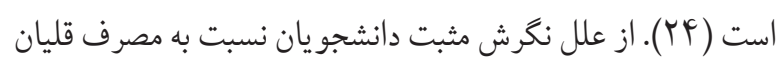

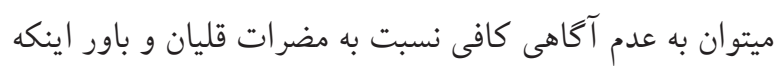
مو اد دخانى در كاهش اضطراب، استرس و خستكى آنها نقش دارد،

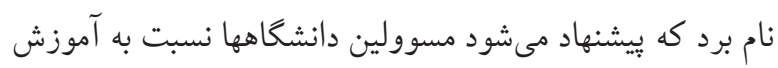

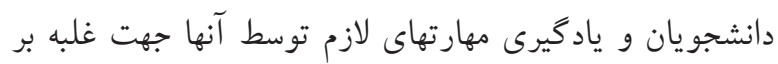
خشم، اضظر اب و خستكى و على الخصوص در دانشجو يان ساكن

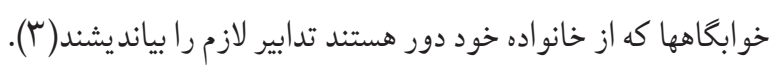
نتايج يزوهش جر كزى و همكارانش همسو با نتايج ما نشان

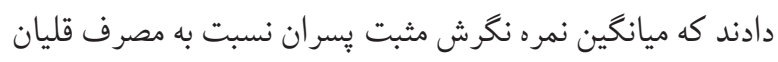


استعمال قليان كه اين روزها شاهد افزايش مصرف آن در بين جوانان

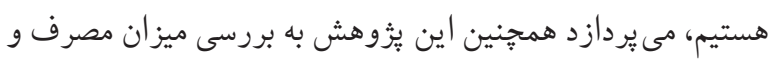

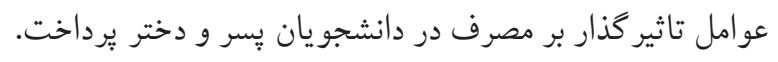
محدوديت هاى مطالعه

اين مطالعه تنها در دانشجويان يكى از دانشكاههاى كشور صورت كرفته است و ممكن است نتايج آن براى ساير دانشكاهها

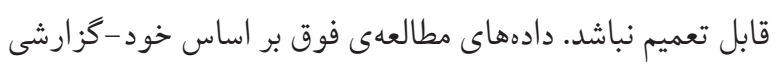
جمع اورى گرديده است. اكرجه سعى شده كه با جلب اطمينان مشاركت كنند كان پاسخ هاى واقعى آنها دريافت شود ولى ممكن

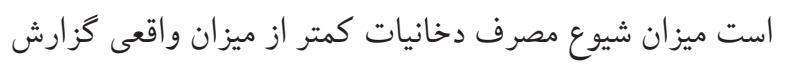

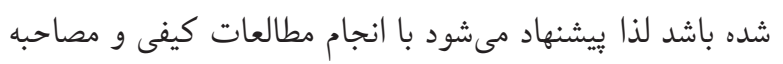

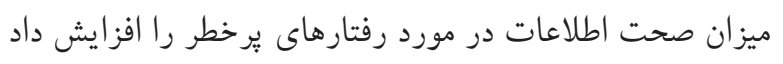

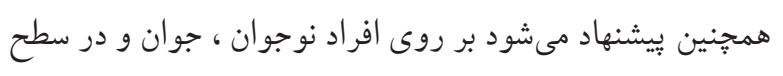

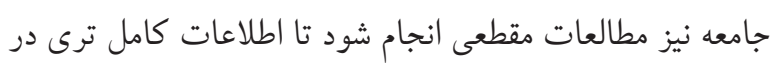

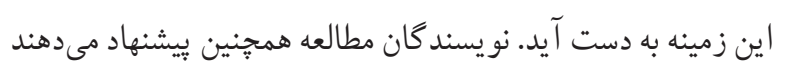

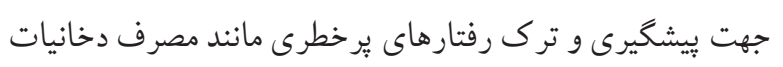

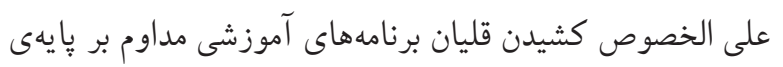

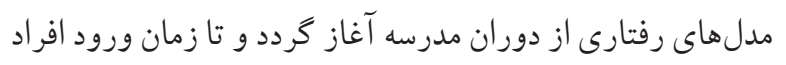

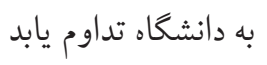
نتيجه كيرى با توجه به نتايج بدست آمده كه نشان دهنده شيوع قابل توجه

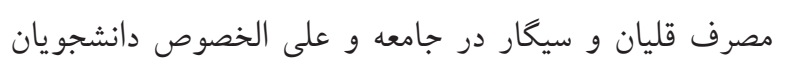

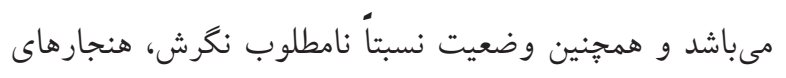

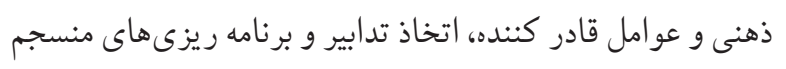

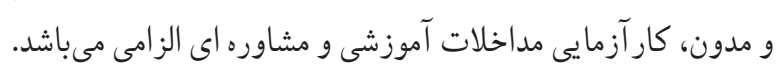
همجنين لازم است قو انينى براى كاهش دسترسى افراد إد به دخانيات و مصرف اين مو اد در اماكن عمومى تصو يب و اجرايى شود. تقدير و تشكر متر متر مقالهى حاضر بركرفته از طرح تحقيقاتى مصوب كميته تحقيقات

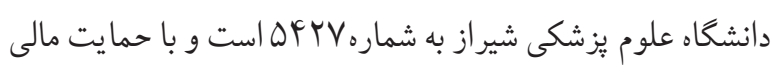

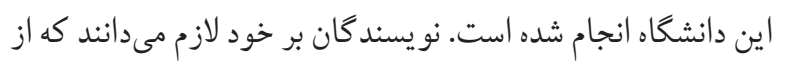

در اين مطالعه سهولت دسترسى به قليان و ارزان بودن آن به ته ترتب به عنوان مهمترين عوامل قادر كننده در جهت استعمال قليان بيان شدند. در مطالعه جر كزى نيز همسو با نتايج مطالعات

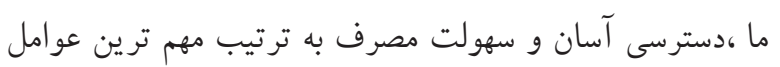

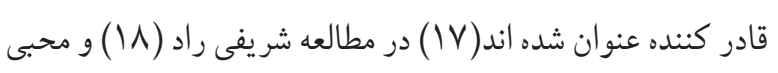

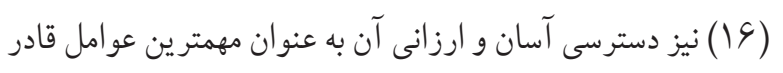

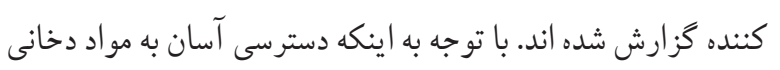

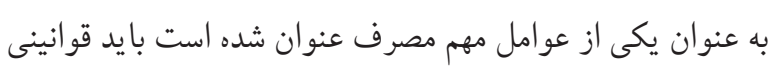

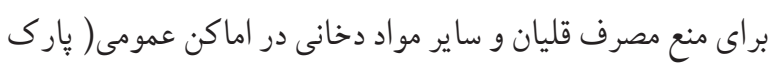
ها،

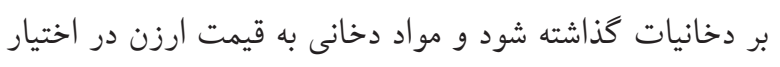

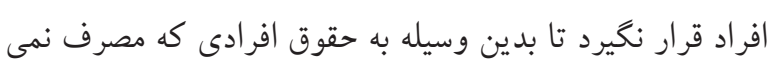
كنند ولى در معرض خطرات ناشى از دود دسته دوم و دسته سوم آن هستند توجه لازم شود(YV)

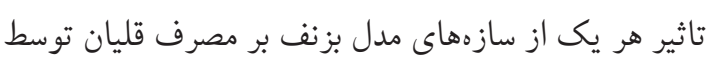
آزمون ركر سيون لجستيك مورد بررسى قرار گرفت. نتايج نشان داد

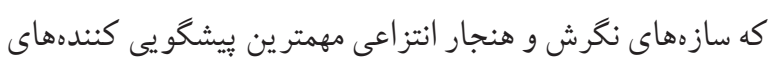

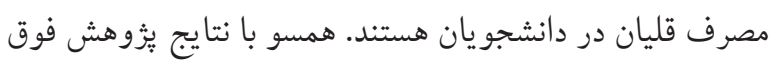

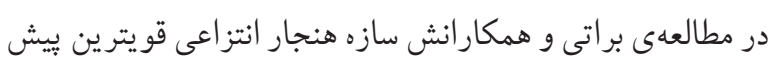

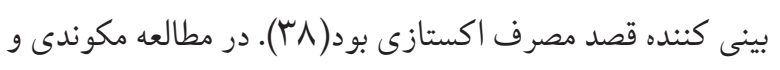

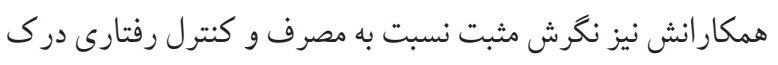

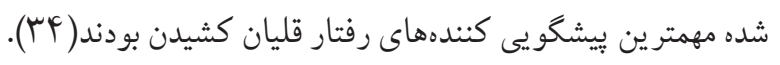

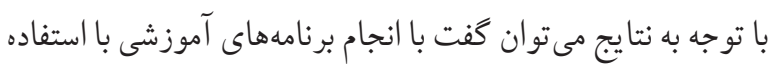

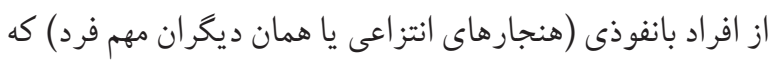

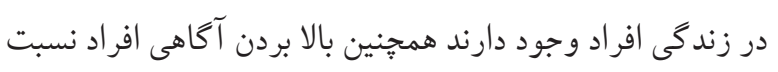

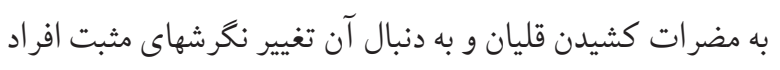

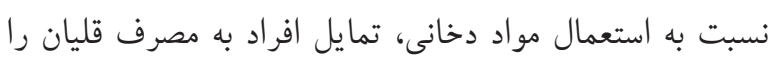
مى توان كاهش داد. نقاط قوت مطالعه از نقاط قوت مطالعه انجام يُّوهش با مدل بزنف بود كه به

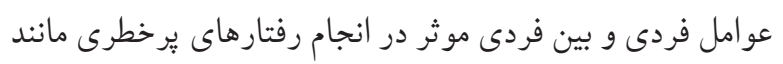




$$
\text { تضاد منافع تهم تمامى نو يسند گان در اين مطالعه يكسان است و هيجگونه }
$$

\section{References}

1. Khoie M, Jafary Nodoushan Z, Alipour Nodoushan K. Investigating the health literacy of addicts referring to addiction treatment centers in Qom city and its relationship with demographic variables. Journal of Health Literacy. 2019;4(3):13-20. doi.org/10.22038/jhl.2019.42225.1073

2. Momenabadi V, Iranpour A, Khanjani N, Mohseni M. Effect of educational intervention on water pipe behaviour of students in dormitories of Kerman Medical University: BASNEF Model. Journal of Health Promotion Management. 2015;4(3):12-22.

3. Joveyni H, Dehdari T, Gohari M, Gharibnavaz H. The survey of attitudes, subjective norms and perceived behavioral control of college students about hookah smoking cessation. J Health Systems Research. 2013;8(7):1-11.

4. Kandela P. Nargile smoking keeps Arabs in Wonderland. Lancet. 2000;365(9236):1175. https://doi.org/10.1016/S0140-6736(05)72871-3

5. Hadidi KA, FI. M. Nicotine content in tobacco used in hubblebubble smoking. Saudi Med J. 2004;25(7):912-7.

6. Smith-Simone S, Maziak W, Ward KD, 2008;10(2):3938. ET. Waterpipe tobacco smoking: knowledge, attitudes, beliefs, and behavior in two U.S. samples. Nicotine tob res J. 2008;10(2):393-8. https://doi.org/10.1080/14622200701825023 PMid:18236304 PMCid:PMC3215239

7. Daniel j, p. A. Waterpipe smoking in students: Prevalence, risk factors, symptoms of addiction, and smoke intake. Evidence from one British university. . BMC Public Health. 2008;8(174):1-5. https://doi.org/10.1186/1471-2458-8-174 PMid:18498653 PMCid:PMC2413225

8. Roskin j, p. A. Canadian and English students' beliefs about waterpipe smoking: a qualitative study. BMC Public Health 2009;9(10):1-7. https://doi.org/10.1186/1471-2458-9-10 PMid:19134220 PMCid:PMC2628878

9. Almerie MQ, Matar HE, Salam M, Morad A, Abdulaal M, Koudsi A, et al. Cigarettes and waterpipe smoking among medical students in Syria: a cross-sectional study. . J Tuberc Lung Dis. 2008;12(9):1085-91.

10. Douglas KA, Collins JL, Warren C, Kann L, Gold R, Clayton $\mathrm{S}$, et al. Results from the 1995 National College Health Risk Behavior Survey. J Am Coll Health. 1997;46(2):55-66. https://doi.org/10.1080/07448489709595589

$$
\text { مسئولين دانشكدهها و دانشگاه علوم يزشكى مورد مطالعه و تمامى }
$$

\section{PMid:9276349}

11. Taraghijah S, Hamidieh M, N. Y. Predictive factors and waterpipe cigarette smoking in Governmental university students. Research in Medical 2011;34(4):249-56.

12. Alaee R, Kadivar P, Mohammadkhani S, Sarami G, S. A. The prevalence of smoking hookah, alcohol and drug use and driving among high school students. Journal of Research on Addiction 2011;5(18):99-114.

13. Momenabadi V, Kaveh $\mathrm{MH}$, Hashemi SY. Effect of educational intervention on intention of University students' disuse of Hookah smoking: BASNEF model. JOURNAL OF SUBSTANCE USE. 2017(2):1-6.

14. Momenabadi V, Kaveh MH, Hashemi SY, Borhaninejad VR. Factors Affecting Hookah Smoking Trend in the Society: A Review Article. Addict Health J. 2016;8(2):1-13.

15. Peyman N, Rezai-Rad M, Tehrani H, Gholian-Aval M, Vahedian-Shahroodi M, Heidarian Miri H. Digital Media-based Health Intervention on the promotion of Women's physical activity: a quasi-experimental study. BMC Public Health. 2018;18(1):134. https://doi.org/10.1186/s12889-018-5025-5 PMid:29334970 PMCid:PMC5769504

16. Mohebi S, Shahsiah M, Matlabi M, M. K. The Study of Factors Influencing Smoking among Male University Students in Kermanshah. . Knowledge \& Health J 2010;5(2,3):5-11.

17. Charkazi A, Heshmati H, O. N. Explaining Smoking among Students at Golestan University of Medical Sciences Based on BASNEF Model. . Journal of Health Systems Research 2011;7(6):98-3.

18. Sharifirad G, A. K. Effective factors on smoking behavior based on BASNEF model in students dormitory at Isfahan University of Medical Sciences. Zahedan J Res Med Sci. 2008;11(4):267-71.

19. Diclemente RJ, RA. C. Health Behavior Theory for Public Health: Principles, Foundations, and Applications. 1 ed: Jones \& Bartlett Publishers.; 2013.

20. Glanz K, Rimer BK, K. V. Health behavior and health education: theory, research, and practice. 4 ed2008.

21. Conner M, P. N. Predicting health behaviour: Research and Practice With Social Cognition Models. . Elsevier Science Ltd. 1996;24(3):229-36. https://doi.org/10.1016/S0925-7535(97)81483-X

22. Lee YO, Hebert CJ, Nonnemaker JM, AE. K. Multiple 
tobacco product use among adults in the United States: Cigarettes, cigars, electronic cigarettes, hookah, smokeless tobacco, and snus. Preventive Medicine J. 2014;62:14-9. https://doi.org/10.1016/j.ypmed.2014.01.014 PMid:24440684

23. Dehdari T, Jafari A, H. J. Students' perspectives in Tehran University of Medical Sciences about factors affecting smoking hookah. . Razi Journal of Medical Sciences 2012;19(95):1-24.

24. Fayazbakhsh A, Shokoohi M, L. J. Assessment of Tobacco Use Khowledge, Attitude and Practice of "Tehran University of Medical Sciences" Students. Journal of Isfahan Medical School. 2010;27(103):822-30.

25. Shojaa M, Jouybari L, Ghorbani M, Sanakoo A, Shojaee $\mathrm{H}$, al. e. Prevalence and Cause of Smoking among the Dormitories Students in Gorgan University of Medical Sciences. Pejouhandeh. 2010;15(3):123-28.

26. Momenan AA, Sarbandizaboli F, Etemadi A, F. A. Pattern of waterpipe (ghalyan) use among intermediate and high school students: a cross- sectional study in Tehran, Iran. Payesh Health Monit J 2007;6(2):135-44.

27. Nakhostin Roohi B, N. V. Cardio-Respiratory Fitness, Body Composition and Waterpipe Smoking in Physical Education Students. . J Ardabil Univ Med Sci 2011;11(3):282-91.

28. Al Moamary MS, Al Ghobain MA, Al Shehri SN, Alfayez Al, Gasmelseed AY, MS. A-H. The prevalence and characteristics of water-pipe smoking among high school students in Saudi Arabia. Journal of infection and public health 2012;5(2):159-68. https://doi.org/10.1016/j.jiph.2012.01.002 PMid:22541263

29. Fielder LF, Carey KP, MP. C. Prevalence, frequency, and initiation of hookah tobacco smoking among firstyear female college students: A one-year longitudinal study. . Addictive behaviors J. 2012;37:221-4. https://doi.org/10.1016/j.addbeh.2011.10.001 PMid:22037255 PMCid:PMC3230723

30. Sharifirad G, Charkazi A, Ghourchaei AB, Shahnazi $H$, Moudi M, GM. K. Smoking Behavior Based on Stages of
Change Model Among Iranian Male Students in 2009-2010 Academic Year. . Zahedan J Res Med Sci 2012;14(1):13-7.

31. Abedini S, Kamalzadeh takhti H, Sadeghifar E, A. Sv. Assessment Cigarette smoking status of Bandar Abbas University of Medical Sciences, 2007. . Hormozgan Medical Journal. 2007;11(4):297-302.

32. Tavafian S, Aghamolaei T, S. Z. Application a between theory model of stages of change in cigarette smoking behavior in the adult population of Bandar Abbas. Payesh 2009;8(3):263-69.

33. Ramezankhani A, Sarbandi F, Zarghi A, Heidari G, M. M. Pattern of Cigarette Smoking Adolescent Students in Tehran. Pejouhandeh. 2010;15(3):115-22.

34. Makvandi Z, Sharifi M, Barati M. Assessment of Factors Associated With Hookah Consumption Among College Students of Asad Abad City Base on The Theory of Planned Behavior (TPB) in 2015-2016. Iran J Helth Educ Health Promot. 2018;5(4):270-9. https://doi.org/10.30699/acadpub.ijhehp.5.4.270

35. Fazelpour SF, Moghaddam Nia MT, F. NZ. Study on Attitude of Students in Guilan University of Medical Sciences toward Smoking. . Scientific Journal of Forensic medicine 2004;33:25-9.

36. Kardia SL, Pomerleau CS, Rozek LS, Marks JL. Association of parental smoking history with nicotine dependence, smoking rate, and psychological cofactors in adult smokers. . Addict Behav. 2003;28(8):1447-52. https://doi.org/10.1016/S0306-4603(02)00245-9

37. Zareipour MA, Sadeghi R, Sadeghi Tabatabaei SA, Seyedi S. Effective Factors on Smoking Based on Basnef Model in Male Student in Tehran medical sciences University in 2009. Journal of nursing and midwifery urmia university of medical sciences 2011;9(1):23-9.

38. Barati B, Allahverdipour H, Moinei B, Farhadinasab A, H. M. Evaluation of Theory of Planned Behavior-Based Education in Prevention of MDMA (ecstasy) use among University Students. Medical Journal of Tabriz University of Medical Sciences and Health Services 2011;33(3):209. 